\title{
PLANEJAMENTO GOVERNAMENTAL E GESTÃO DA DÍVIDA PÚBLICA
}

\section{José Mauricio Conti}

Professor de Direito Financeiro da Faculdade de Direito da USP-SP. Mestre, Doutor e Livre-docente pela Faculdade de Direito da USP. Juiz de Direito em São Paulo.

Gabriel Loretto Lochagin

Professor de Direito Econômico e Financeiro da Faculdade de Direito da USP-RP. Mestre e Doutor pela Faculdade de Direito da USP.

\section{SUMÁRIO}

Introdução - 1. A gestão da dívida pública - 2. A dívida pública no orçamento brasileiro - 3. A dívida pública no sistema de planejamento orçamentário da administração pública -4 . Síntese conclusiva Referências. 


\section{INTRODUÇÃO}

A dívida pública brasileira é uma questão central no âmbito das finanças públicas, e sua dimensão a coloca em um patamar de importância que exige tratamento diferenciado no que tange à sua gestão. E torna imperativo que seja abrangida pelo sistema de planejamento governamental, sem o que informações essenciais para estabelecer os objetivos a serem traçados e o caminho a ser percorrido para atingi-los fiquem empobrecidos e comprometam o sistema de planejamento.

No entanto, vê-se não estar a dívida pública adequadamente inserida no sistema de planejamento governamental, especialmente em seu aspecto orçamentário. As leis que consolidam o sistema de planejamento orçamentário da administração pública não trazem as informações necessárias e suficientes para um dos itens mais significativos na gestão das finanças públicas atualmente.

Um déficit de transparência que exige ser mais bem estudado.

De modo geral, já foi suficientemente enfatizada a necessária articulação entre planejamento plurianual e orçamento para boa parte das despesas governamentais - ainda que o cotidiano da gestão pública seja tão desencontrado das previsões normativas que muito haja a ser feito na prática. Mesmo que todos os entes federativos cumpram seus deveres constitucionais de elaboração de todas as leis orçamentárias, a adesão das previsões e da execução orçamentárias aos programas plurianuais fica muito aquém de qualquer nível aceitável, dado o crônico problema do planejamento governamental no país. Quando se trata da dívida pública, no entanto, há ainda uma dificuldade adicional: sequer existem as previsões plurianuais com as metas e diretrizes para o orçamento financeiro, referente aos pagamentos dos compromissos oriundos da dívida.

Apenas como cogitação, seria possível argumentar que os compromissos financeiros devem ser atendidos à medida que têm seus prazos vencidos, o que tornaria inócuo que o PPA traçasse metas para os desembolsos orçamentários com a dívida. Esse é um ponto de vista equivocado, lançado apenas para mostrar a natureza do problema. Equivocado porque parte do pressuposto de que o planejamento poderia prever metas a menor, ou seja, abaixo do fluxo necessário para satisfazer os credores. Não é apenas para isso que servem o planejamento e a gestão da dívida. Ao contrário, a perspectiva de prazos médio e longo contribui não apenas para organizar os desembolsos como também para oferecer condições de que o Estado tome diversas decisões financeiras relevantes. Por exemplo: qual deve ser a estrutura de maturidade dos títulos públicos? Quando convém emitir títulos indexados? Qual deve ser, enfim, a composição da dívida pública? Essas e outras decisões relativas ao benchmarking da dívida pública brasileira apenas podem ser adequadamente tomadas tendo em vista as metas para o endividamento, tanto em seus níveis como nos tipos das obrigações que os compõem. 
Apenas, portanto, com planejamento adequado é que é possível exercer alguma forma de previsão estratégica e operacional sobre o volume, a composição e o cronograma de pagamentos da dívida pública. Essas decisões pertencem não apenas ao universo do curto prazo mas, sobretudo, ao planejamento de vigência mais longa. Como já destacado em trabalho sobre a gestão da dívida pública federal, há uma necessária articulação entre as políticas econômicas estruturais sobre os níveis de endividamento e as decisões orçamentárias de médio e curto prazos ${ }^{1}$.

O orçamento desempenha, com relação à dívida, função que vai além do registro contábil. Dadas as diversas funções do orçamento, não seria de se supor que as dotações para o serviço dos compromissos financeiros escapassem a esse caráter multifacetado, que confere às leis orçamentárias não apenas o aspecto técnico, mas o de instrumentos de planejamento ${ }^{2}$. A previsão dos fluxos de recursos para os encargos do crédito público é uma decisão financeira que parte de diagnósticos e, sobretudo, indica objetivos relacionados ao financiamento do Estado. Esses objetivos se referem à continuação das fontes de financiamento (a partir da segurança quanto às previsões de pagamento) e, se bem geridos, controlam os riscos envolvidos e instrumentalizam as decisões sobre a composição do endividamento. Trata-se, dessa forma, de decisão de preservação do crédito público e de controle de cenários variáveis de risco.

Essas decisões fazem parte da gestão da dívida pública. Analisando-se os custos e o ambiente das decisões, o planejamento orçamentário do setor público é viável mediante a adequada gestão da dívida. Do contrário, dada a forte participação dos encargos financeiros nas despesas do setor público, a falta de planejamento sobre esses cenários poderia tornar o orçamento excessivamente vulnerável à conjuntura e a eventuais choques ${ }^{3}$. A atividade de gestão da dívida se ocupa de que os dados disponíveis sejam capazes de informar as decisões de política econômica e fazer com que a ação dos atores administrativos envolvidos se dê conforme os objetivos do plano de financiamento do setor público.

Conforme já especificado em outro trabalho, e em extensão ao que foi dito acima, um dos principais objetivos dos processos de gestão dos pagamentos da

1 LOCHAGIN, Gabriel; DOMINGUES, Juliana. O sistema de integração das normas constitucionais de limitação ao endividamento público. Revista da Universidade Federal de Passo Fundo, v. 31, n. 3, set./out. 2017. p. 561-563.

2 A respeito das funções do orçamento no atual contexto constitucional, ver LOCHAGIN, Gabriel. A execução do orçamento público: flexibilidade e orçamento impositivo. São Paulo: Blucher, 2016. p. 48-56.

3 No orçamento de 2018 (Lei n. 13.587/2018), a despesa com o refinanciamento da dívida pública correspondeu a R \$ 1,16 trilhão, ou o equivalente a 32,37\% das despesas autorizadas para a União. 
dívida pública é preservar as condições necessárias para maximizar o interesse, atual e futuro, de investidores públicos e privados em oferecer capitais ao Estado interessado, além de definir o perfil da dívida e satisfazer as necessidades financeiras do Estado ${ }^{4}$. Essa definição parte daquela oferecida pelo Fundo Monetário Internacional, que qualifica a atividade de gestão da dívida pública como um processo de elaboração e execução de estratégias que tenham por fim "aumentar a quantidade requerida de financiamento, alcançar os objetivos de riscos e custos, e cumprir outros objetivos de gestão de dívida pública que o governo possa ter estabelecido, tais como desenvolver e manter um mercado eficiente para os títulos públicos" .

\section{A GESTÃO DA DÍVIDA PÚBLICA}

Desde um ponto de vista histórico, não é nova a ideia de que a gestão da dívida pública conta com uma institucionalidade própria, de forma a viabilizar o adequado planejamento de suas características e de seu montante. Com institucionalidade quer-se dizer que não foram poucos os casos em que se criaram estruturas administrativas próprias que pudessem realizar, com algum grau de autonomia, os objetivos de gestão da dívida. Na Suécia, o Departamento da Dívida Pública (Rijksgälden) existe desde $1789^{6}$. Ainda anteriormente, o Banco da Inglaterra começou a desempenhar essas mesmas funções em seu país?. Essa tradição administrativa não se tornou a regra geral, é verdade, muito embora tenha permitido analisar os impactos que a divisão funcional e o caráter técnico das decisões poderiam ter para a qualidade do financiamento público. Foi apenas na década de 1990 que as perspectivas de governança global levaram organismos multilate-

4 LOCHAGIN, Gabriel; DOMINGUES, Juliana. O sistema de integração das normas constitucionais de limitação ao endividamento público, cit., p. 561-563.

5 No original, "[s] overeign debt management is the process of establishing and executing a strategy for managing the government's debt in order to raise the required amount of funding, achieve its risk and cost objectives, and to meet any other sovereign debt management goals the government may have set, such as developing and maintaining an efficient market for government securities" (INTERNATIONAL MONETARY FUND; THE WORLD BANK. Guidelines for public debt management. Washington, D.C.: 2001, p. 2).

6 Cf. DYSON, K. States, debt and power: "saints" and "sinners" in European history and integration. Oxford: Oxford University Press, 2014. p. 381 e seguintes.

7 Diversas práticas do Banco da Inglaterra, destinadas a manter o valor dos títulos públicos e facilitar sua circulação, permitindo ainda a tomada de massiva quantidade de crédito, foram extensamente analisadas já por SMITH, A. The wealth of nations. London: Bantam Classics, 2003 (1776). esp. p. 1159-1160. 
rais, tais como o FMI, em âmbito global, e instituições comunitárias, como a União Europeia, a estabelecer boas práticas para seus membros, indicando parâmetros para o planejamento estratégico da dívida do setor público. Nisto, recuperaram algo da experiência de racionalização e transparência que instituições anglo-saxãs e escandinavas haviam perfilado séculos antes.

Um conceito-chave para compreender a técnica de racionalização da gestão da dívida pública é a profissionalização - etapa instrumental e anterior ao planejamento propriamente dito. Seria preciso criar condições para que o diagnóstico da situação posta pudesse amparar objetivos claros em instituições fortes, cuja autonomia decisória é respeitada e legitimada pelas autoridades políticas.

Para neutralizar as pressões de curto prazo do setor político, por exemplo, a recomendação é a de que a autoridade administrativa tenha autonomia para a parte operacional da gestão da dívida - lidar com os dealers primários, ou seja, as instituições financeiras habilitadas para subscrever diretamente as emissões do governo. Essa autonomia não impede que o poder de controle e supervisão hierárquicos se exerça por autoridade superior, apta a definir diretrizes de atuação. $\mathrm{O}$ órgão de gestão da dívida, no entanto, tem os meios à sua disposição para persegui-las. É o caso do UK Debt Management Office (Reino Unido), da Agence France Trésor (França) e da Deutsche Finanzagentur (Alemanha) ${ }^{8}$.

Nos anos 1990, a defesa do planejamento governamental da dívida, mediante atuação de estruturas administrativas especializadas, visava neutralizar a ascendência de esferas políticas externas na execução de políticas econômicas definidas pelas autoridades constituídas. A definição macropolítica sujeita-se a determinados procedimentos que admitem, pela própria constituição democrática do Estado, a formulação conforme programas de governo. O objetivo, no entanto, seria fazer com que a perseguição desses objetivos pudesse se dar em ambiente de análise objetiva das condições de financiamento do Estado e de acordo com objetivos de equilíbrio mais amplo do que a lógica de curto prazo permitiria. Questões como a avaliação de risco e a fragmentação do poder decisório - incapaz de integrar formar soluções consistentes - impactavam a qualidade das políticas da dívida e, muitas vezes, forneciam informações ruins para a estimativa das dotações orçamentárias ao serviço da dívida, com a simulação de custos menores do que aqueles necessários para a manutenção das condições de crédito 9 .

Nesse sentido,

8 Novamente, ver DYSON, K. States, Debt and power, cit., p. 381 e seguintes.

9 WHEELER, G. Sound practice in sovereign debt management. Washington, D.C.: The World Bank, 2004. p. 2. 
[a] importância de se adotar boas práticas na gestão da dívida pública como meio para assegurar, ou ao menos não afetar, a estabilidade macroeconômica se tornou clara especialmente após a ocorrência de vários eventos que atingiram adversamente os mercados emergentes no final da década de 1990 . Nesse debate, é central a necessidade de se desenhar estratégias adequadas e coerentes para a administração da dívida que levem em conta, dentre outros elementos, a composição ótima da dívida no longo prazo, os riscos inerentes a tais estratégias e o compromisso com o desenvolvimento do mercado de dívida ${ }^{10}$.

As atividades de gestão da dívida podem ser divididas em executivas e operacionais. A gestão executiva da divida pública é a etapa em que se definem as "regras do jogo" pelos níveis mais altos, algo que pode ser feito pelo órgão central. Nesse patamar de decisão, são dadas as direções para a organização das políticas relativas à dívida no contexto da política econômica geral, levando-se em conta as implicações fiscais, monetárias, cambiais e creditícias. Sua dimensão é, portanto, macroeconômica e macroadministrativa.

A gestão executiva desdobra-se, ainda, em três dimensões ${ }^{11}$ :

a) Função regulatória: definição do ambiente legal em que se desenvolvem as atividades de coordenação, registro, análise, controle e operação, a partir de fluxos de informação satisfatórios. O principal objetivo dessa função é definir com clareza as responsabilidades organizacionais, as regras e os procedimentos das unidades de gestão.

b) Função política: diz respeito à formulação da política da dívida pública, bem como das estratégias a serem seguidas em conjunto com as demais políticas econômicas do país. Exemplo de definição política estratégica é definir quais setores deverão ter acesso a financiamento externo, assim como traçar metas de limite máximo para categorias de endividamento (como, v.g., o externo). O objetivo dessa função é definir, de forma equilibrada e sustentável, a estratégia nacional de endividamento.

c) Função de mobilização dos recursos humanos: como se trata de atividade altamente especializada, a regulação e a definição de políticas da

10 ALVES, Luiz Fernando; SILVA, Anderson Caputo. Planejamento estratégico da dívida pública federal. In: SILVA, Anderson Caputo; CARVALHO, Lena O.; MEDEIROS, Otávio L. (Org.). Dívida pública: a experiência brasileira. Brasília: Secretaria do Tesouro Nacional/Banco Mundial, 2009. p. 149.

11 De acordo com a classificação de BORRESEN, Pal; COSIO-PASCAL, Enrique. Role and organization of a debt office. New York: UNCTAD, 2002. p. 4-6. 
dívida exigem recrutamento e treinamento adequado de servidores capacitados, bem como, em algumas situações, a contratação e a supervisão de consultores externos com expertise em áreas específicas - principalmente quando se tratar de operações com novos instrumentos dos mercados financeiros ou atividades de auditoria. Mais amplamente, diz respeito também à provisão dos recursos materiais necessários. O objetivo dessa função é prover a atividade de gestão da dívida dos meios e do pessoal necessários.

A gestão operacional da dívida pública, por sua vez, realiza as atividades de execução das diretrizes e objetivos definidos pelos órgãos de gestão executiva. Essa atividade do "dia a dia"12 envolve funções de registro, análise, controle e operação.

a) Função de registro: trata-se da coleta e registro de informações, uma das frequentes fontes de baixa qualidade na gestão da dívida, pois muitas dessas informações podem ser pouco acuradas ou desatualizadas. Essa função também é conhecida como a atividade de back office, que oferece o fluxo de dados necessário para a adequada definição de políticas de endividamento.

b) Função de análise: fornece elementos de análise das informações registradas pelo órgão de back office. A partir da agregação de dados, utiliza-se deles para definir as melhores opções de endividamento. Também é responsável, em nível desagregado, pelo exame dos instrumentos específicos de endividamento, ou outros elementos importantes dos títulos públicos, como os prazos de maturidade. Essa é a atividade de middle office, ao qual compete a análise das diferentes possibilidades relativas ao endividamento e aos seus instrumentos, bem como a manutenção ou modificação dos instrumentos financeiros adotados em determinado momento.

c) Função de operação: divide-se em três fases, que são as de negociação, utilização dos empréstimos e serviço. A negociação tem lugar anteriormente à contratação e busca atingir os objetivos definidos na estratégia financeira a partir das funções analíticas do midlle office. A negociação é entabulada tanto em relação a empréstimos novos como à reestruturação da dívida antiga. Também é conhecida como atividade de front office, que atua para obter as transações do portfólio da dívida em condições estratégicas. A utilização dos empréstimos e o serviço da dí-

12 INTERNATIONAL MONETARY FUND. External debt statistics: guide for compilers and users. Washington, D.C.: 2003. p. 203. 
vida, por sua vez, são funções desempenhadas pelo orçamento público, que serve de instrumento de definição sobre a aplicação dos recursos obtidos mediante financiamento e sobre os pagamentos dos compromissos assumidos.

A divisão orgânica da gestão da dívida brasileira (isto é, a repartição de competências entre os órgãos que fazem a gestão da dívida) atende à categorização acima, embora não haja órgãos de gestão com a independência formal conferida aos debt offices de outros países, também citados.

As instituições acima encontram-se organizadas no âmbito do Poder Executivo, e a prática internacional se reflete em órgãos próprios construídos em cada administração nacional. Relevante também é a institucionalização do processo decisório acerca do endividamento público, tornando-o democrático e transparente, para o que se faz necessária a participação do Poder Legislativo, não ficando as decisões concentradas exclusivamente no âmbito do Poder Executivo

A responsabilidade orgânica pela gestão da dívida no Brasil situa-se, em âmbito federal, na estrutura do Ministério da Economia (anteriormente Ministério da Fazenda), que exerce a função de órgão central. As funções executivas são desempenhadas ainda pelos órgãos da Secretaria do Tesouro Nacional (STN) responsáveis: a Coordenação-Geral de Controle da Dívida Pública (Codiv), a Coordenação-Geral de Planejamento Estratégico da Dívida Pública (Cogep), e a Coordenação-Geral de Operações da Dívida Pública (Codip). Esse padrão divide as funções administrativas em três partes funcionalmente distintas: front office, middle office e back office. Em conjunto com a Subsecretaria da Dívida Pública, os três órgãos compõem o Comitê de Gerenciamento da Dívida Pública.

De grande relevância para a gestão da dívida pública é o Acórdão n. 1.798/2015, do Tribunal de Contas da União, que teve por objeto "produzir e estruturar o conhecimento sobre os processos de gestão da dívida pública, conhecer os seus gargalos, riscos associados e elaborar uma matriz de auditoria com ações de controle a serem realizadas no curto e médio prazo" ${ }^{13}$.

Os elementos de controle de riscos e custos relacionados à gestão da dívida são realçados pelo TCU como intrínsecos ao seu processo de planejamento. In verbis,

[a] gestão da dívida pública é um processo complexo que envolve a criação e implementação de uma estratégia para a gestão prudente da dívida do governo, a fim de atender às suas necessidades de financiamento, bem como

13 BRASIL. Tribunal de Contas da União. Acórdão n. 1.798/2015-Plenário. Relator: Ministro José Múcio Monteiro. Plenário, Brasília, 22 de julho de 2015. 
a definição de objetivos de custo e risco, e quaisquer outros objetivos relacionados, tais como desenvolvimento e manutenção de mercados eficientes para os títulos do governo ${ }^{14}$.

Nessa decisão, que teve como objetivo "produzir e estruturar o conhecimento sobre os processos de gestão da dívida pública, conhecer os seus gargalos, riscos associados e elaborar uma matriz de auditoria com ações de controle a serem realizadas no curto e médio prazo", foram identificados riscos relevantes à gestão da dívida pública federal. São os seguintes:

- $\quad$ R1 - risco de irregularidade e ineficiência causada pelos repasses ao BNDES;

- $\quad$ R2 - risco de aumento do endividamento em decorrência do excesso de empréstimos ao setor elétrico;

- $\quad$ R3 - risco de liquidez em decorrência do curto prazo médio de maturação da dívida;

- $\quad$ R4 - risco de sustentabilidade provocado pelo alto custo do serviço da dívida;

- $\quad$ R5 - risco de liquidez causado pela grande concentração de títulos com vencimento em "cabeça” de trimestre (janeiro, abril, julho, outubro);

- $\quad$ R6 - risco de impacto financeiro relevante causado por falhas na apropriação e na gestão de passivos contingentes;

- $\quad$ R7 - risco de transparência devido à falta de consolidação e quitação da dívida de órgãos públicos, gerando uma série de "esqueletos” da dívida que, se somados, podem impactar a dívida total;

- $\quad$ R8 - risco de sustentabilidade e de crédito pela falta de superávit primário suficiente para diminuir a proporção dívida bruta/PIB ${ }^{15}$.

Nesse sentido, a definição dos benchmarkings deve passar por processo de planejamento em que a distribuição das tarefas entre os órgãos de gerenciamento deve ser delimitada o suficiente para atribuir responsabilidades claras, mas também deve se integrar para avaliar os requisitos precisos de manutenção do financiamento do setor público em condições ótimas ${ }^{16}$.

14 BRASIL. Tribunal de Contas da União. Acórdão n. 1.798/2015-Plenário, cit., parágrafo 27.

15 BRASIL. Tribunal de Contas da União. Acórdão n. 1.798/2015-Plenário, cit., p. 30.

16 Além do mencionado acórdão, outros casos de atuação do TCU em vista do controle da gestão da dívida federal são analisados em LOCHAGIN, Gabriel; MOUTINHO, Donato. Controle 


\section{A DÍVIDA PÚBLICA NO ORÇAMENTO BRASILEIRO}

No caso brasileiro, o financiamento orçamentário da dívida tem diversos objetivos concomitantes, como já ressaltado em texto anterior ${ }^{17}$. Entre esses objetivos está a previsão de recursos orçamentários para o serviço da dívida pública com diversos objetivos concomitantes: a redução de prazos concentrados de maturidade; a otimização da vida média da dívida pública; a redução do custo dos empréstimos; a substituição gradual da dívida externa reestruturada; a abertura dos mercados e o desenvolvimento dos mercados de títulos públicos.

No Brasil, o principal instrumento de planejamento da dívida pública é o Plano Anual de Financiamento (PAF), que divulga tanto para a sociedade como para os responsáveis oficiais as ações do Tesouro. Sua periodicidade é anual e se trata, atualmente, de documento central para as diretrizes e os objetivos da dívida pública federal.

É, de fato, no PAF que se evidencia o plano estratégico do setor público para cumprir as finalidades da gestão da dívida pública federal, de forma a cumprir

(...) o papel de reduzir as incertezas quanto à gestão da dívida pública $\mathrm{e}$ possíveis implicações nas tomadas de decisões dos distintos agentes econômicos. A estratégia de financiamento é estruturada com o objetivo de redução de custos no longo prazo, concomitantemente à manutenção de níveis prudentes de risco. Para tanto, almeja-se uma composição bem diversificada para a DPF, preferencialmente com maior proporção de títulos remunerados por índices de preços e prefixados de prazos mais longos, embora o balanço entre custos e riscos no curto prazo comporte presença relevante para os instrumentos com juros flutuantes nas emissões da dívida mobiliária ${ }^{18}$.

Entre as diretrizes para a política econômica voltada à dívida interna encontra-se, explicitamente, "o aperfeiçoamento da composição da DPF, a estratégia contempla a emissão de títulos prefixados (LTN e NTN-F) e títulos remunerados por índice de preços (NTN-B). A emissão de NTN-B corrobora também com a

da gestão da dívida pública federal. Revista do Mestrado em Direito da Universidade Católica de Brasília, v. 11, n. 2, p. 45-82, jul.-dez. 2017.

17 LOCHAGIN, Gabriel; DOMINGUES, Juliana. O sistema de integração das normas constitucionais de limitação ao endividamento público, cit., p. 575.

18 BRASIL. Ministério da Fazenda, Secretaria do Tesouro Nacional. Dívida Pública Federal: Plano Anual de Financiamento 2019. Brasília: Secretaria do Tesouro Nacional, 2019, p. 4. 
diretriz de alongamento da DPF, uma vez que estes títulos possuem, em média, prazos mais longos"19.

Com relação à dívida externa, prevê-se

(...) a política de atuação qualitativa no mercado externo, com o objetivo de consolidar curvas de financiamento externas líquidas e eficientes, que possam servir de referência para o setor corporativo. Atualmente, a dívida soberana brasileira apresenta pontos de referência em dólar, euro e real. Para o aprimoramento da curva de juros externa, o Tesouro Nacional mantém o programa de resgate antecipado de títulos, podendo atuar ainda por meio de outras operações de gerenciamento do passivo externo, com vistas a retirar do mercado títulos menos eficientes. Dessa forma, o Tesouro contribui para o desenvolvimento da estrutura a termo de taxas de juros não apenas no mercado doméstico, mas também no mercado externo, em linha com as diretrizes da $\mathrm{DPF}^{20}$.

Além do PAF, devem ser apontados, como instrumentos de planejamento e transparência da gestão da dívida, o Relatório Anual da Dívida Pública, que traz a análise daquilo que foi realizado nesse âmbito durante o exercício, o Relatório Mensal da Dívida Pública, o qual apresenta dados sobre a composição da dívida pública federal, o Cronograma Mensal de Emissões, publicado mensalmente para divulgar as datas de liquidação e de realização dos leilões, e os Informes da Dívida e outros documentos ocasionais, com informações relevantes julgadas oportunas quando seja necessário expô-las.

Esses objetivos se traduzem, em algum momento, na definição do serviço das obrigações financeiras, feita tanto na fase de elaboração quanto na de execução do orçamento público. Como já afirmado,

(...) na fase de elaboração, durante a previsão das despesas financeiras de acordo com as metas de resultado relacionadas ao serviço da dívida, ou seja, a partir da definição do montante a ser adimplido da dívida pública de acordo com as diretrizes estabelecidas pela Lei de Diretrizes Orçamentárias e as previsões da Lei de Responsabilidade Fiscal. Durante a fase de execução, por sua vez, o planejamento estratégico ocorre de acordo com o Plano Anual de Financiamento, divulgado em janeiro de cada ano, que permitirá o acompanhamento da execução orçamentária conforme as diretrizes, estratégias

19 BRASIL. Ministério da Fazenda, Secretaria do Tesouro Nacional. Dívida Pública Federal: Plano Anual de Financiamento 2019, cit., p. 11.

20 BRASIL. Ministério da Fazenda, Secretaria do Tesouro Nacional. Dívida Pública Federal: Plano Anual de Financiamento 2019, cit., p. 14. 
e metas nele estabelecidas, orientando a necessidade de geração de receitas pela emissão de títulos ${ }^{21}$.

Caso as dotações se mostrem insuficientes, seu reforço se dá pelos mecanismos usuais de flexibilização, com os recursos oriundos das fontes permitidas para os créditos adicionais ${ }^{22}$, com a exigência de que sejam compatíveis com as metas de resultado primário estabelecidas no Anexo de Metas Fiscais da LDO. Aliás, a LDO contém previsões relativas ao serviço da dívida pública. Cabe-lhe estabelecer prioridades para a aplicação dos recursos obtidos mediante operações de crédito, orientando as despesas que serão atendidas pelas emissões de títulos públicos.

Com relação à classificação das despesas financeiras no orçamento, utilizam-se distintos critérios, que identificam o responsável pela programação (critério institucional), a finalidade dos recursos (critério programático), a ação do governo a ser executada (critério funcional) e o efeito econômico da despesa (critério da natureza da despesa).

As unidades administrativas responsáveis pela execução do orçamento da dívida pública se apresentam com algumas particularidades, pois a noção administrativa mais comum de "órgão" difere da concepção orçamentária e financeira nesse aspecto; ou, dito melhor, os órgãos com competência para gerir a dívida pública não necessariamente coincidem com aqueles orçamentariamente identificados com a realização das despesas ${ }^{23}$. Isso porque, no caso da destinação de recursos relativos à dívida, os órgãos responsáveis têm grau maior de abstração do que aquele usualmente identificado com setores estruturados da administração pública que concentram determinadas competências. Não é o único caso, havendo outros em que o orçamento prevê como órgãos as "Transferências a Estados, Distrito Federal e Municípios" e a "Reserva de Contingência", tratando como uma estrutura administrativa aquilo que mais se aproxima da própria atividade da Administração. Sua apresentação separada, no entanto, revela maior transparência dessas despesas, que ficariam em meio a outras caso fossem incluídas sem destaque. No caso da dívida pública federal, as despesas com o serviço da dívida

${ }^{21}$ LOCHAGIN, Gabriel; DOMINGUES, Juliana. O sistema de integração das normas constitucionais de limitação ao endividamento público, cit., p. 577.

22 De acordo com o art. 43, $\mathbb{S} 1^{\circ}$, são o superávit financeiro, o excesso de arrecadação, os resultantes da anulação total ou parcial de outras dotações e o produto de operações de crédito autorizadas.

${ }^{23}$ Celso Antônio Bandeira de Mello apresenta definição suficientemente ampla de órgão que não necessariamente os identifica com um conjunto de competências. Assim, "órgãos são unidades abstratas que sintetizam os vários círculos de atribuições do Estado” (Curso de direito administrativo. 26. ed. São Paulo: Malheiros, 2009. p. 140). 
destinadas a amparar programas setoriais são designadas aos respectivos ministérios, mas todas as outras são incluídas em dois órgãos sob a supervisão do Ministério da Economia: os "Encargos Financeiros da União (EFU)" e o "Refinanciamento da Dívida Pública Mobiliária Federal”, cujas despesas são executadas pela Secretaria do Tesouro Nacional.

A classificação funcional, por sua vez, identifica as áreas de realização das despesas (por exemplo, saúde), e têm sua divisão em funções e subfunções já previamente determinadas. Aqui também há uma particularidade orçamentária, pois há, para as despesas que não geram diretamente um bem ou serviço (tais como educação e transportes, novamente a título de exemplo), uma função abstrata, a dos "Encargos Especiais". Nela se incluem obrigações financeiras diversas, como as subfunções "Refinanciamento da Dívida Interna" e "Refinanciamento da Dívida Externa”, dentre outras.

A classificação programática apresenta nível maior de agregação das ações do governo, de forma a mostrar determinado resultado, e aqui se tem uma integração própria do orçamento ao planejamento estabelecido em programas plurianuais. De acordo com o sistema de classificação dos programas, eles se subdividem em projetos, atividades e operações especiais.

Projetos são os instrumentos de programação para alcançar os objetivos de um programa, a partir de operações limitadas no tempo e das quais resulte um produto final que expanda ou aperfeiçoe a ação do governo; já as atividades também são instrumentos de programação para alcançar os objetivos de um programa, com a diferença de que envolvem operações contínuas e permanentes necessárias para a manutenção da ação do governo ${ }^{24}$. Por sua vez, das operações especiais constam despesas que não contribuem para a manutenção das ações de governo e das quais não resulta um produto ou contraprestação direta sob a forma de bens e serviços.

É justamente nessa categoria que são incluídos os programas orçamentários da dívida pública, permitindo-se localizar diversas finalidades do seu pagamento.

A classificação pela natureza admite, ainda, que se conheçam os efeitos econômicos das despesas a partir da categoria econômica (corrente ou de capital), dos grupos da despesa, da modalidade de aplicação e outras classificações menores, tais como os elementos e outras menores. De acordo com previsão do art. 13 da Lei n. 4.320/64, o pagamento de juros e demais encargos da dívida pública são classificados como despesas correntes. De fato, as leis orçamentárias preveem

24 Ver Portaria n. $42 / 99$ do Ministério do Planejamento, Orçamento e Gestão. Além disso, GIACOMONI, James. Orçamento público. 15. ed. São Paulo: Atlas, 2010. p. 97. 
como grupo das despesas correntes justamente os "Juros e Encargos da Dívida". A seu turno, as despesas de capital incluem os gastos com a amortização da dívi$\mathrm{da}$, que por sua vez incluem despesas com o pagamento do principal e com o refinanciamento.

Também as receitas obtidas com as operações de crédito recebem tratamento orçamentário específico. No caso da dívida pública federal, as receitas originadas de operações de crédito (façam parte da dívida mobiliária ou contratual) são classificadas como receitas de capital, pelo critério segundo a natureza. Sob o Código 2.0.0.0.00.00 (Receitas de Capital) encontram-se tanto as "Operações de Crédito" (2.1.0.0.00.00) como a "Amortização de Empréstimos" (2.3.0.0.00.00).

Segundo a fonte dos recursos, agrupam-se as receitas de acordo com sua destinação, isto é, com determinada finalidade definidas pelo orçamento ou por outra determinação legal. $\mathrm{O}$ vínculo estabelecido entre a receita e o atendimento de determinadas finalidades é, assim, estabelecido pela identificação da fonte dos recursos no orçamento. Em nível maior de abrangência, essas destinações podem ser classificadas como primárias, quando seu montante é dirigido ao resultado primário, e não primárias ou financeiras, quando não incluídas nesse cálculo. As receitas financeiras são aquelas provenientes das operações de crédito, das aplicações financeiras e dos juros; outras receitas, como as tributárias e as originadas do exercício de atividade econômica não financeira pelo Estado (como as receitas patrimoniais, agropecuárias, industriais e de serviços), são classificadas como primárias.

Tradicionalmente, as fontes destinadas de forma usual ao pagamento da dívida pública federal são previstas, no orçamento, como os "Recursos Ordinários" (100), os "Recursos de Concessões" (129) e os "Dividendos de Empresas Estatais" (197), os quais compõem o cálculo do superávit primário do governo federal; o "Resultado Positivo do Banco Central" (152), transferido ao Tesouro assim que aprovado pelo Conselho Monetário Nacional; o "Retorno de Refinanciamento de Dívida de Médio e Longo Prazos" (159), que diz respeito aos pagamentos de outros entes da federação ou de empresas estatais, originados do endividamento assumido perante o governo federal quando da renegociação da dívida externa; a "Reforma Patrimonial - Alienação de Bens" (162) e o "Retorno de Refinanciamento da Dívida de Estados e Municípios" (173), este último proveniente de pagamentos de estados e municípios ao governo federal, originados da renegociação de suas dívidas internas no âmbito do programa de renegociação de 1997; a "Remuneração da Conta Única" (188); e, finalmente, os "Recursos do Fundo de Amortização da Dívida" (197), provenientes da venda de ações ou quotas de empresas públicas sem transferência do controle acionário.

Vê-se, do quadro exposto, que a contabilização da dívida no orçamento público não é simples, e essa complexidade tende a obscurecer os dados relacionados à mensuração e à própria gestão da dívida pública. 


\section{A DÍVIDA PÚBLICA NO SISTEMA DE PLANEJAMENTO ORÇAMENTÁRIO DA ADMINISTRAÇÃO PÚBLICA}

Um dos aspectos que se pretende destacar nesse texto, e cujo aperfeiçoamento se mostra necessário em matéria de endividamento público, é o do planejamento da dívida pública, especialmente no seu aspecto orçamentário.

Há instrumentos recentes que indicam a preocupação com a questão, com especial ênfase para o Plano Anual de Financiamento, ao qual já se fez referência e que voltará a ser analisado. Trata-se de documento que abrange o planejamento da dívida pública em seu aspecto mais amplo, estabelecendo as diretrizes estratégicas para o financiamento de médio e longo prazo da dívida pública federal. Falta, contudo, uma referibilidade mais clara e precisa nas leis orçamentárias de planejamento, tornando precário o respaldo jurídico dessas informações, e tornando falho o sistema de planejamento orçamentário da dívida pública ${ }^{25}$.

O Plano Anual de Financiamento - PAF é elaborado no Ministério da Economia pela Secretaria do Tesouro Nacional - portanto, no âmbito do Poder Executivo Federal, sem a participação do Poder Legislativo. Trata-se, por conseguinte, de documento não sujeito ao crivo do Poder Legislativo, e, embora destinado a cumprir a função de dar transparência à gestão da dívida, o fato de ser elaborado unilateralmente, sem parâmetros legais que o regulem, faz dele um instrumento por demais frágil para cumprir o papel que lhe cabe de conferir segurança jurídica, transparência e credibilidade à sociedade e aos agentes econômicos e sociais ${ }^{26}$.

O controle praticamente absoluto da Secretaria do Tesouro Nacional na gestão da dívida pública, especialmente sobre o seu planejamento, afasta o controle democrático sobre uma das mais expressivas e relevantes despesas públicas, alijando o Poder Legislativo das decisões a esse respeito.

Além do déficit de transparência, temos também um déficit democrático cuja permanência não se justifica na atual conjuntura e no sistema vigente de planejamento, gestão e controle da atividade financeira do Estado.

A participação do Poder Legislativo no planejamento da dívida pública hoje praticamente se restringe à aprovação, na Lei de Diretrizes Orçamentárias, da meta anual de resultado nominal e primário da dívida pública para o exercício

25 Sobre a delimitação dos conceitos de planejamento governamental e planejamento orçamentário, ver CONTI, José Mauricio. Planejamento orçamentário da administração pública. Tese (Titularidade) - Faculdade de Direito da USP, São Paulo, 2017. esp. p. 44-49.

${ }^{26}$ O TCU já chamou a atenção para essa deficiência ao evidenciar que sua publicação não é institucionalizada, não estando instituída por Portaria do Ministério da Fazenda (atualmente Ministério da Economia) (Acórdão n. 1.798/2015, p. 7, item 38). 
seguinte e os dois subsequentes, tal como previsto no art. $4^{\circ}, \mathbb{S} \int 1^{\circ}$ e $2^{\circ}$, II da Lei de Responsabilidade Fiscal (LC 101/2000). Valores esses que não poderão mais ser objeto de deliberação pelo Poder Legislativo por ocasião da apreciação do projeto de lei orçamentária, em face da vedação constitucional do art. $166, \mathbb{S} 3^{\circ}$, II, $b$ ("As emendas ao projeto de lei do orçamento anual ou aos projetos que o modifiquem somente podem ser aprovadas caso indiquem os recursos necessário, admitidos apenas os provenientes de anulação de despesa, excluídas as que incidam sobre serviço da dívida”). Embora essa decisão seja de suma importância, torná-la uma das poucas em que o Poder Legislativo tenha participação é apequenar o aspecto democrático das decisões em matéria de endividamento público.

O principal instrumento de planejamento orçamentário da administração pública é o Plano Plurianual - PPA, que tem sido historicamente omisso nas questões relacionadas à dívida pública, como se pode constatar, omissões essas que agravam sobremaneira a questão do planejamento na gestão da dívida pública. E cabe ao PPA dispor sobre as diretrizes, objetivos e metas da administração pública para as despesas de capital e outras delas decorrentes $\left(\mathrm{CF}\right.$, art. $\left.165, \mathbb{S} 1^{\circ}\right)$, entre as quais deveriam estar as despesas com amortização da dívida pública (Lei n. 4.320/64, art. 13), trazendo clareza e transparência sobre esses gastos, e submetendo-os ao controle financeiro institucional e social.

Nos programas contemplados pelo PPA Federal 2016-2019, apenas o Programa 2039 ("Gestão da Política Econômica, Garantia da Estabilidade do Sistema Financeiro Nacional e Melhoria do Ambiente de Negócios”) traz alguma referência à questão da dívida pública, e mesmo assim com pouco interesse para os fins de se obter informações úteis e voltadas ao planejamento nessa matéria. O objetivo 1095 do referido programa, "Aprimorar a gestão de receitas e despesas para garantir o equilíbrio fiscal”, tem entre seus propósitos

Cumprir a meta de resultado fiscal para o Governo Central estabelecida na Lei de Diretrizes Orçamentárias (LDO) - Meta 049N; Aprimoramento da gestão do endividamento público e gestão de haveres da União - Meta 057S; Minimização dos custos da dívida pública federal, mantendo seus riscos em níveis prudenciais - Meta 57U; e Realização regular de análises da sustentabilidade da dívida bruta e líquida do setor público, incluindo análise de sensibilidade e estresse - Meta 057X.

Ou seja, pouco colaboram para o conhecimento e definição do montante e dos rumos da dívida pública federal, não sendo por consequência um instrumento útil para essas finalidades.

E a dimensão do endividamento público é informação extremamente relevante para a condução dos rumos das finanças públicas, como o próprio governo reconhece: "O tamanho da dívida pública é essencial para se avaliar a saúde das 
finanças públicas do país. Quando a dívida é demasiadamente elevada, o governo pode perder a capacidade de honrar seus compromissos e de manter as políticas públicas" 27 . Soma-se a isso a já conhecida e referida dificuldade em delimitar e mensurar a dívida pública, que o governo também reconhece precisa ser superada:

Mas, para se discutir o tamanho é preciso antes entender de que dívida estamos falando. No Brasil, há mais de um conceito e cada um deles tem sua relevância a depender da análise que estamos fazendo. Passemos aos principais. No Plano Anual de Financiamento trabalhamos com a Dívida Pública Federal (DPF). Esta abrange apenas a dívida do Governo Federal em mercado, incluindo os títulos da dívida interna (cerca de 95\%) e os títulos e contratos da dívida externa. Essa dívida é emitida e controlada pelo Tesouro Nacional, que é responsável ainda por seu pagamento. Sua origem são os déficits públicos passados e presentes ${ }^{28}$.

O planejamento da dívida pública é, portanto, extremamente complexo, exigindo não somente sua conceituação e delimitação precisa como também o estabelecimento de critérios para sua mensuração, etapas ainda não satisfatoriamente vencidas, o que precede a necessária inserção nos instrumentos de planejamento orçamentário da administração pública. Atos indispensáveis para a transparência e o controle democráticos que se fazem necessários, e não só não podem prescindir da participação do Poder Legislativo na definição dos rumos e diretrizes, como também devem permitir o controle institucional e social dessa despesa extremamente expressiva do Estado.

A estratégia para o financiamento e sustentabilidade da dívida pública precisa ser submetida ao crivo do Parlamento, até para que seja cientificado dos riscos e também assuma por eles as responsabilidades decorrentes das decisões tomadas.

E não poucas. A forma de composição da dívida, os prazos, espécies e características dos títulos e respectivas formas de remuneração, juros, estratégias de alongamento e pagamento, retorno esperado e efetivo do lançamento de títulos no mercado, são apenas alguns exemplos das graves decisões que têm de ser tomadas pelos gestores da dívida pública, que envolvem alto grau de discricionariedade e riscos, que afetam as políticas monetária e fiscal, e não podem ser insuscetíveis de participação e controle parlamentar e social.

A trajetória da dívida pública, que depende de todos os fatores mencionados, é fundamental para o planejamento de médio e longo prazos das ações governa-

27 BRASIL. Ministério da Fazenda, Secretaria do Tesouro Nacional. Dívida Pública Federal: Plano Anual de Financiamento 2017. Brasília: Secretaria do Tesouro Nacional, 2017. p. 39.

28 BRASIL. Ministério da Fazenda, Secretaria do Tesouro Nacional. Dívida Pública Federal: Plano Anual de Financiamento 2017, cit., p. 39. 
mentais e assegurar sua sustentabilidade, com reflexos diretos no orçamento público, tornando imperiosa previsão orçamentária que os leve em consideração, e que não podem se restringir ao horizonte do curto prazo, sob pena de comprometer todo o sistema de planejamento orçamentário da administração pública.

Muitos países têm seus sistemas de gerenciamento da dívida pública submetidos anualmente a auditorias por órgãos independentes que apresentam seus relatórios ao Parlamento ${ }^{29}$, evidenciando a indispensabilidade dessa integração da dívida pública ao sistema de planejamento orçamentário e inclusão nas respectivas leis que o materializam.

\section{SIINTESE CONCLUSIVA}

Vê-se que a gestão e o planejamento da dívida pública estão em nítida evolução, com aperfeiçoamento de seus mecanismos de funcionamento e até mesmo transparência. No entanto, há ainda um forte déficit de institucionalização desses instrumentos, que no mais das vezes não estão materializados em documentos jurídicos adequados, e sequer previstos em lei. Portanto, deixam todo esse arcabouço fundamental para a gestão e controle de um dos mais relevantes aspectos da atividade financeira do Estado fragilizado sob o ponto de vista jurídico, gerando um déficit democrático e de transparência, causador de insegurança jurídica e falta de participação e controle por parte do Poder Legislativo e da sociedade.

\section{REFERÊNCIAS}

ALVES, Luiz Fernando; SILVA, Anderson Caputo. Planejamento estratégico da dívida pública federal. In: SILVA, Anderson Caputo; CARVALHO, Lena O.; MEDEIROS, Otávio L. (Org.). Dívida pública: a experiência brasileira. Brasília: Secretaria do Tesouro Nacional/Banco Mundial, 2009.

BANDEIRA DE MELLO, Celso Antônio. Curso de direito administrativo. 26. ed. São Paulo: Malheiros, 2009.

BEVILACQUA, Afonso; GARCIA, Márcio. Debt management in Brazil: evaluation of the real plan and challenges ahead. International Journal of Finance and Economics, v. 7, $\mathrm{n}^{\mathrm{o}} 1$, p. 15-35, 2002.

BLOMMENSTEIN, H.; TURNER, P. In: OCDE. Interactions between sovereign debt management and monetary policy under fiscal dominance and financial instability.

OECD Working Papers on Sovereign Borrowing and Public Debt Management, Washington, D.C., n. 3, 2012.

29 INTERNATIONAL MONETARY FUND; THE WORLD BANK. Guidelines for public debt management: accompanying document. Washington, D.C.: 2002, p. 27. 
BORRESEN, Pal; COSIO-PASCAL, Enrique. Role and organization of a debt office. New York: UNCTAD, 2002.

BRASIL. Ministério da Fazenda, Secretaria do Tesouro Nacional. Dívida Pública Federal: Plano Anual de Financiamento 2015. Brasília: Secretaria do Tesouro Nacional, 2015.

BRASIL. Ministério da Fazenda, Secretaria do Tesouro Nacional. Dívida Pública Federal: Plano Anual de Financiamento 2017. Brasília: Secretaria do Tesouro Nacional, 2017.

BRASIL. Ministério da Economia, Secretaria do Tesouro Nacional. Dívida Pública Federal: Plano Anual de Financiamento 2019. Brasília: Secretaria do Tesouro Nacional, 2019.

BRASIL. Tribunal de Contas da União. Acórdão n. 1.798/2015 - Plenário. Relator: Ministro José Múcio Monteiro. Plenário, Brasília, 22 de julho de 2015.

CONTI, José Mauricio. Planejamento orçamentário da administração pública. Tese (Titularidade) - Faculdade de Direito da USP, São Paulo, 2017.

DYSON, K. States, Debt and power: "saints" and "sinners" in European history and integration. Oxford: Oxford University Press, 2014

GIACOMONI, James. Orçamento público. 15. ed. São Paulo: Atlas, 2010.

GIAVAZZI, Francesco; MISSALE. Public debt management in Brazil. NBER Working Paper Series, National Bureau of Economic Research, Washington, D.C., n. 10394, mar. 2004.

INTERNATIONAL MONETARY FUND. External debt statistics: guide for compilers and users. Washington, D.C.: 2003.

INTERNATIONAL MONETARY FUND; THE WORLD BANK. Guidelines for public debt management. Washington, D.C.: 2001.

INTERNATIONAL MONETARY FUND; THE WORLD BANK. Guidelines for public debt management: accompanying document. Washington, D.C.: 2002.

LOCHAGIN, Gabriel; MOUTINHO, Donato. Controle da gestão da dívida pública federal. Revista do Mestrado em Direito da Universidade Católica de Brasília, v. 11, n. 2, p. 45-82, jul.-dez. 2017.

LOCHAGIN, Gabriel; DOMINGUES, Juliana. O sistema de integração das normas constitucionais de limitação ao endividamento público. Revista da Universidade Federal de Passo Fundo, v. 31, n. 3, set./out. 2017.

NOGUEIRA, Jozélia; CONTI, José Mauricio. Planejamento de longo prazo e a justiça intergeracional. Revista Internacional Consinter de Direito, n. VII, p. 217-2322, 2. sem. 2018.

PÁLSSON, Anne-Marie. Does the degree of relative risk aversion vary with household characteristics? Journal of Economics Psychology, v. 17, n. 6, p. 771-787, 1996. 
PASSOS, Antônio de Pádua Ferreira; CASTRO, Priscila de Souza Cavalcante. In: SILVA, Anderson Caputo; CARVALHO, Lena de Oliveira; MEDEIROS, Otávio Ladeira. Dívida pública: a experiência brasileira. Brasília: Secretaria do Tesouro Nacional, 2009.

ROCHA, Karen de Lima. Estrutura institucional e eventos recentes na administração da dívida pública federal. In: SILVA, Anderson Caputo; CARVALHO, Lena Oliveira de; MEDEIROS, Otávio Ladeira. Dívida pública: a experiência brasileira. Brasília: Secretaria do Tesouro Nacional, 2009.

SANT'ANA, Wilma Luiza. Orçamento da dívida pública: um novo enfoque. Brasília: ESAF, 1996.

SILVA, Aline Dieguez B. de Menezes; MEDEIROS, Otávio Ladeira. Conceito e estatísticas da dívida pública. In: SILVA, Anderson Caputo; CARVALHO, Lena O.; MEDEIROS, Otávio L. (Org.). Dívida pública: a experiência brasileira. Brasília: Secretaria do Tesouro Nacional/Banco Mundial, 2009. p. 101-128.

SMITH, A. The wealth of nations. London: Bantam Classics, 2003 (1776).

WHEELER, G. Sound practice in sovereign debt management. Washington, D.C.: The World Bank, 2004. 